\title{
Influence of previous experience on the feeding habits of larval weakfish Cynoscion regalis
}

\author{
Victoria Pryor Connaughton, Charles E. Epifanio
}

University of Delaware, College of Marine Studies, 700 Pilottown Road, Lewes, Delaware 19958, USA

\begin{abstract}
Larval weakfish Cynoscion regalis (Bloch \& Schneider) were examined to determine the influence of dietary conditioning on prey selection. Experiments were conducted with larvae in each of 4 age classes $(8,11,14$ and $17 \mathrm{~d}$ posthatching). Larvae were given a monospecific diet of either large rotifers, small rotifers, or brine shrimp nauplii for $5 \mathrm{~d}$ prior to an experiment. Larvae were then given a choice between the familiar prey and one of the other prey types. In separate experimental trials, the conditioned prey was administered in 3 different proportions $(10,25$ or $40 \%$ ) of the total ration. Larvae consumed both prey types in all trials, but analysis of gut contents often showed a significant deviation from expected ratios of the 2 prey. In experiments with the 2 size classes of rotifer, all ages of larvae chose the familiar prey. In the large rotifer/brine shrimp experiments, larvae 11 and $14 \mathrm{~d}$ posthatching could be conditioned to large rotifers; however, larvae $17 \mathrm{~d}$ posthatching always chose brine shrimp, even when initially conditioned to rotifers. In comparisons of small rotifers and brine shrimp, larvae never showed a preference for rotifers. These results indicate that effects of dietary conditioning on prey selection vary with larval age and relative prey size.
\end{abstract}

\section{INTRODUCTION}

Many studies examining feeding in larval fish have addressed the influence of prey characteristics such as size, color, swimming speed, or abundance (Govoni et al. 1983, 1986, Boisclair \& Leggett 1989, Pryor \& Epifanio 1993). However, predator experience can also exert a major influence on the feeding process (Mathias \& Li 1982, Dill 1983). With development fish larvae eat larger prey items, and older larvae are more efficient foragers whose increased energetic demands may be compensated for by the consumption of larger prey (Brett \& Groves 1979, Hunter 1980). However, older larvae may continue to eat small items even when larger prey are available (Hansen \& Wahl 1981, Checkley 1982, Dill 1983, Stoecker \& Govoni 1984). Continued preference for smaller items may result from high capture success with smaller, more familiar prey (Stoecker \& Govoni 1984, Dutton 1992). While there has been considerable study of the influence of predatory experience on such factors as capture success, feeding success and reaction dis- tance (Ware 1971, Dutton 1992), there has been little work on the effect of dietary conditioning on selective feeding or on the ability of fish larvae to switch to a novel prey (Lindberg \& Doroshov 1986, Mills et al. 1987).

Weakfish support an important commercial and recreational fishery in the Middle Atlantic Bight, with Delaware Bay (USA) providing a major nursery ground for the species (Mercer 1983). Important prey for weakfish larvae in Delaware Bay include polychaete larvae, invertebrate eggs and all life stages of copepods (Goshorn \& Epifanio 1991). Laboratory experiments have shown that prey size and abundance are major determinants of prey selection by larval weakfish (Pryor \& Epifanio 1993). In the present study, we have examined the influence of dietary conditioning on selective feeding by weakfish larvae. In particular, we investigated the facility of weakfish larvae to switch from familiar to novel prey items. In the rest of the paper, we use the term 'conditioning' to indicate the process by which larvae become familiar with a prey type 


\section{MATERIALS AND METHODS}

Larvae and prey. Adult Cynoscion regalis (Bloch \& Schneider) were collected from the spawning grounds in southern Delaware Bay during May and June 1992. Immediately after capture, the gametes from at least 3 males and a like number of females were mixed haphazardly in a 191 bucket of filtered seawater. In the laboratory, fertilized eggs were washed with seawater to remove any extraneous debris and placed in 401 conical containers (cones) at $20^{\circ} \mathrm{C}$ and $30 \% \mathrm{~S}$ on a photoperiod of $14 \mathrm{~h}$ light and $10 \mathrm{~h}$ dark (Pryor \& Epifanio 1993). Eggs hatched after $48 \mathrm{~h}$ and larvae began exogenous feeding on the third day posthatching ( $3 \mathrm{dph}$ ). At that time larvae were fed a diet of wild zooplankton $\left(5000 \mathrm{l}^{-1}\right)$ until needed for the experiments. Zooplankton ranged in size from 53 to $253 \mu \mathrm{m}$, and the assemblage consisted predominantly of polychaete larvae, barnacle nauplii and all life stages of copepods.

Weakfish larvae are planktonic, and larval duration is approximately $3 \mathrm{wk}$ in Delaware Bay (Cope 1991). Separate experimental trials were conducted with larvae from each of 4 age classes $(8,11,14$ and $17 \mathrm{dph})$. These larvae ranged from 2.8 to $6.2 \mathrm{~mm}$ in mean notochord length (Pryor \& Epifanio 1993). Prey items included both large and small size classes of the rotifer Brachionus plicatilis as well as newly hatched brine shrimp Artemia sp. nauplii (San Francisco Bay Brand). Rotifers were cultured in the laboratory, and large and small size classes were obtained by sieving. Mean lengths and widths of each prey type were determined with a computer-assisted image-analysis system (Pryor \& Epifanio 1993). Large rotifers were $216 \times 162 \mu \mathrm{m}$, small rotifers were $160 \times 107 \mu \mathrm{m}$ and brine shrimp were $449 \times 167 \mu \mathrm{m}$.

Experimental protocol. For 5 d before an experiment, larvae were cultured in $40 \mathrm{l}$ cones and fed a monospecific diet of either large rotifers, small rotifers or brine shrimp. Larvae used in experimental trials at $8 \mathrm{dph}$ began the diet at $3 \mathrm{dph}$. These larvae were too small to eat brine shrimp nauplii; thus, experimental trials with brine shrimp did not include 8 dph larvae. All experiments were conducted in $40 \mathrm{l}$ cones identical to those used in rearing and conditioning. Cones were fitted with a bottom drain to allow easy removal of larvae at the termination of an experiment. Larvae were placed into experimental cones $\left(2.5 \mathrm{l}^{-1}\right)$ on the night prior to an experiment. This allowed larvae to clear their guts and acclimate to the containers.

In each experiment larvae were given a choice between a familiar prey item and a novel prey item; these 2 prey items were termed a 'prey pair'. We conducted reciprocal experiments comparing 3 different prey pairs: large rotifers/small rotifers, large rotifers/ brine shrimp and small rotifers/brine shrimp. Each reciprocal experiment included 2 sets of trials. In the first set, the initial item in the prey pair, e.g. large rotifers, was the familiar prey and the second item, e.g. small rotifers, was the novel prey. In the companion set, the items were presented in a reciprocal manner, i.e. small rotifers as familiar prey and large rotifers as novel prey. In each trial the familiar prey was administered in a different proportion $(10,25$ or $40 \%)$ of the total ration; each proportion was considered an experimental treatment. The total ration was always 10000 $\mathrm{l}^{-1}$, which is the highest zooplankton abundance measured during a recent survey on the weakfish spawning grounds in Delaware Bay (Goshorn 1990). For comparisons of the 2 size classes of rotifer, a complete experimental set consisted of 12 trials (4 age classes $x$ 3 treatments). For comparisons of rotifers and brine shrimp, a complete set consisted of 9 trials (3 age classes $\times 3$ treatments).

Experimental trials were randomly assigned to individual cones, with only 1 cone used for each experiment. After a $3 \mathrm{~h}$ feeding period, the cones were drained and larvae retained on a $253 \mu \mathrm{m}$ sieve. Larvae were preserved on $5 \%$ frozen formaldehyde, which prevents both regurgitation and defecation (Pryor \& Epifanio 1993). The larvae were later transferred to $70 \%$ ethanol prior to analysis of gut contents. The total number of each prey item consumed by each larva was pooled within a given experiment before statistical analysis. We analyzed the frequency of prey occurrence using the binomial probability distribution (Zar 1984) followed by the sequential Bonferroni technique (Rice 1990). This procedure tested whether the observed number of items within the gut contents significantly deviated from the expected ratio $(\alpha=0.05)$, with the expected ratio of prey items equivalent to the proportions of prey items initially presented. Thus, if larvae were not conditioned, we would expect to see prey items eaten in the same proportion as they were administered.

\section{RESULTS}

Larvae consumed both prey types in all experimental trials, but analysis of gut contents often showed a significant deviation from expected ratios. In comparisons of the 2 size classes of rotifer, there was a preference for the conditioned prey. When larvae were conditioned to large rotifers, the proportion of that prey type was greater than expected, regardless of larval age or treatment. In reciprocal trials, the proportion of small rotifers was greater than expected in 10 of 12 cases (Table 1).

In comparisons of large rotifers and brine shrimp, both 11 and 14 dph larvae showed significant effects 
of conditioning on rotifers (Table 2). However, the proportion of brine shrimp in the gut contents increased with larval age, and at 17 dph the larvae consumed significantly more brine shrimp than expected. Larvae conditioned to brine shrimp showed a significant preference for that prey type for all age classes and treatments.

In comparisons of small rotifers and nauplii, larvae always preferred brine shrimp, regardless of conditioning (Table 3 ).

\section{DISCUSSION}

Previous work in our laboratory has shown that weakfish larvae younger than 8 dph display a significant preference for large rotifers over small rotifers, while older larvae prefer brine shrimp over either size of rotifer (Pryor \& Epifanio 1993). In the present experiments we show that these preferences can be reversed by conditioning. For example, when larvae were conditioned to small rotifers, they continued to select this prey type, even from a diet that contained $90 \%$ large rotifers. These results indicate that weakfish larvae can become strongly conditioned to a 'nonpreferred' prey item and can maintain that conditioning in the presence of a favored prey.

This type of response was also seen when 11 and 14 dph larvae were conditioned to large rotifers. In these trials, larvae chose rotifers, even when brine shrimp made up a majority of the administered ration. But in these same trials, 17 dph larvae always chose brine shrimp, regardless of conditioning. Thus it appears that both larval age and the relative size of prey are important in the conditioning process. When the respective prey types are close in size, weakfish larvae of all ages can become conditioned to either prey. However, when the respective prey types differ greatly in size, 17 dph larvae choose the larger prey, regardless of conditioning. This point is further emphasized in comparisons of brine shrimp and small rotifers. These prey types differ very greatly in size, and larvae always chose brine shrimp, regardless of age or conditioning.

The youngest larval age used ( $8 \mathrm{dph}$ ) were fed a monospecific diet until needed for the experiments, while older larvae were maintained on wild zooplank-
Table 1 Cynoscion regalis. Results of experiments in which weakfish larvae were conditioned to large rotifers (LR) or small rotifers (SR) and then given a choice between the conditioned item and another prey item. Values are the percentage of each prey item within the gut contents of all larvae within a given experiment, with total number of prey consumed in parentheses. Asterisks indicate a significant deviation from the expected ratio

Conditioned prey: large rotifers

Larval age (dph) $10 / 90 \begin{array}{cc}\text { Experimental ration (LR/SR) } \\ 25 / 75\end{array}$

$\begin{array}{rlrllll}8 & \cdot 43 / 57(1054) & * 40 / 60 & (689) & \cdot 69 / 31 & (541) \\ 11 & \cdot 25 / 75 & (704) & * 38 / 62 & (272) & \cdot 46 / 54 & (408) \\ 14 & \cdot 58 / 42 & (785) & -49 / 51 & (397) & \cdot 51 / 49 & (534) \\ 17 & \cdot 49 / 51(2249) & \cdot 56 / 44 & (1132) & \cdot 58 / 42 & (2172)\end{array}$

Conditioned prey: small rotifers

Larval age (dph) $10 / 90 \begin{array}{cc}\text { Experimental ration (SR/LR) } \\ 25 / 75\end{array}$

$\begin{array}{rrrrrrr}8 & \cdot 40 / 60 & (299) & \cdot 57 / 43 & (203) & 34 / 66 & (588) \\ 11 & \cdot 51 / 49 & (890) & \cdot 42 / 58 & (849) & \cdot 47 / 53 & (734) \\ 14 & \cdot 38 / 62(1812) & \cdot 61 / 39 & (1356) & 29 / 71 & (1955) \\ 17 & \cdot 50 / 50 & (1395) & \cdot 48 / 52 & (1060) & \cdot 65 / 35 & (829)\end{array}$

Table 2. Cynoscion regalis. Results of experiments in which weakfish larvae were conditioned to large rotifers (LR) or brine shrimp (BS) and then given a choice between the conditioned item and another prey item. Values are the percentage of each prey item within the gut contents of all larvae within a given experiment, with total number of prey consumed in parentheses. Asterisks indicate a significant deviation from the expected ratio

\begin{tabular}{|c|c|c|c|}
\hline \multirow{2}{*}{$\begin{array}{l}\text { Conditioned prey: large } \\
\text { Larval age (dph) }\end{array}$} & arge rotifers & \multicolumn{2}{|c|}{ Experimental ration (LR/BS) } \\
\hline & $10 / 90$ & $25 / 75$ & $40 / 60$ \\
\hline 11 & $\cdot 70 / 30 \quad(274)$ & $-65 / 35 \quad(269)$ & $\cdot 68 / 32 \quad(397)$ \\
\hline 14 & $\cdot 21 / 79 \quad(478)$ & $\cdot 36 / 64 \quad(263)$ & $\cdot 46 / 54 \quad(250)$ \\
\hline 17 & $02 / 98^{\circ}(2230)$ & $02 / 98^{\bullet}(1147)$ & $05 / 95^{\circ}(1523)$ \\
\hline
\end{tabular}

Conditioned prey: brine shrimp

\begin{tabular}{|c|c|c|c|}
\hline \multirow[t]{2}{*}{ Larval age (dph) } & \multicolumn{3}{|c|}{ Experimental ration (BS/LR) } \\
\hline & $10 / 90$ & $25 / 75$ & $40 / 60$ \\
\hline 11 & $\cdot 74 / 26(467)$ & •85/15 (458) & $.85 / 15(343)$ \\
\hline 14 & . $61 / 39(590)$ & $\cdot 83 / 17(405)$ & $\cdot 83 / 17(449)$ \\
\hline 17 & $\cdot 66 / 34(148)$ & $\cdot 86 / 14(197)$ & - $61 / 39(264)$ \\
\hline
\end{tabular}

ton until their conditioning began. By feeding on wild zooplankton, older larvae would have experience with prey items that differ in size, swimming speed, etc. A diverse diet would also allow nutritionally different prey items to be eaten, thereby possibly increasing growth of the larvae. However, though the diets differed, the effects of conditioning toward 1 prey item are consistent over all larval ages tested indicating conditioning may override any effect of pre-experimental diet. 
Table 3. Cynoscion regalis. Results of experiments in which weakfish larvae were conditioned to small rotifers (SR) or brine shrimp (BS) and then given a choice between the conditioned item and another prey item. Values are the percentage of each prey item within the gut contents of all larvae within a given experiment, with total number of prey consumed in parentheses. Asterisks indicate a significant deviation from the expected ratio

\begin{tabular}{|c|c|c|c|}
\hline \multicolumn{4}{|c|}{ Conditioned prey: small rotifers } \\
\hline \multirow[t]{2}{*}{ Larval age (dph) } & \multicolumn{3}{|c|}{ Experimental ration (SR/BS) } \\
\hline & $10 / 90$ & $25 / 75$ & \multirow{2}{*}{$\begin{array}{c}40 / 60 \\
23 / 77 \cdot(663)\end{array}$} \\
\hline 11 & $06 / 94 \quad(626)$ & $11 / 89 \quad(770)$ & \\
\hline 14 & $01 / 99^{\circ}(1632)$ & $01 / 99^{*}(1473)$ & $17 / 83^{\circ}(222)$ \\
\hline 17 & $01 / 99 *(1018)$ & $01 / 99 \cdot(1062)$ & $04 / 96^{\cdot}(565)$ \\
\hline \multicolumn{4}{|c|}{ Conditioned prey: brine shrimp } \\
\hline \multirow[t]{2}{*}{ Larval age (dph) } & \multicolumn{3}{|c|}{ Experimental ration (BS/SR) } \\
\hline & $10 / 90$ & $25 / 75$ & $40 / 60$ \\
\hline 11 & •66/34 (786) & $\cdot 91 / 09(461)$ & *85/15 (367) \\
\hline 14 & $\cdot 81 / 19(381)$ & $\bullet 85 / 15(354)$ & *91/09 (399) \\
\hline 17 & $\cdot 63 / 37(239)$ & •94/06 (524) & *99/01 (439) \\
\hline
\end{tabular}

often characterized by a few numerically dominant taxa, and these taxa can change considerably from patch to patch le.g. Epifanio 1987, Goshorn 1990). However, the selective advantages of conditioning are not clear. In nature larvae encounter numerous prey species in various quantities. If a larva has experience in capturing and consuming several different types of prey, it will be able to forage efficiently within different patches of prey. However, if a larva becomes conditioned to only 1 prey type, its feeding can be reduced if subsequent patches do not contain that item. The decreased growth that accompanies a reduction in feeding can cause an increase in larval stage duration and increased vulnerability to predation (Houde 1987). Additionally, as our experiments were only conducted over a $3 \mathrm{~h}$ period, we do not know how long after

It is tempting to discuss these results in terms of optimal foraging theory, but for any given trial, this would require that larvae perceive both prey types simultaneously and then choose which to attack (Stephens \& Krebs 1986). In fact, fish larvae perceive their prey 1 item at a time, and then 'decide' whether to attack that item (e.g. Pyke et al. 1977. Stephens \& Krebs 1986, O'Brien et al. 1990). In our experiments a 'selected' prey is one that makes up a greater proportion of the gut contents than predicted from its proportion in the available ration. In some cases our results were quite striking. For example, the gut contents of larvae conditioned to small rotifers contained as much as $40 \%$ of that prey type, even when the available ration contained $90 \%$ large rotifers. Clearly this was not a result of differential success of attack, as earlier work has shown very similar swimming speeds and patterns in the 2 classes of rotifers (Pryor \& Epifanio 1993). Differential handling time is also unlikely, as large rotifers are the preferred prey in the absence of conditioning (Pryor \& Epifanio 1993). More likely, conditioning is manifested as a much higher tendency to attack the familiar prey item once it is encountered. To make this 'decision' larvae are clearly able to distinguish between prey items that differ only slightly in size, e.g. large and small rotifers. But, paradoxically, when presented with prey of greatly differing size, larvae appear to 'forget' their conditioning and choose the larger prey. This response is greatest in late-stage larvae, and apparently reflects the general tendency of larvae to attack larger prey as they grow (e.g. Goshorn \& Epifanio 1991).

We do not believe that dietary conditioning is a laboratory artifact, as natural patches of zooplankton are this period the larvae will remain conditioned. Due to the varying stability and composition of zooplankton patches, the duration of the conditioned response may be an important factor in larval fish feeding. Thus, the ability of a larva to retain foraging experience should be accompanied by an ability to switch to novel prey when familiar prey is not present. This ability appears to increase with age in weakfish larvae.

Acknowledgements. We thank M. Burger, M. Connaughton, J. Duffy, D. Evans, B. Jones, P. Rowe, R. Thomas, and J. Welch for help in collecting and culturing the fish larvae. This work was supported by funds from the Wallop-Breaux Sport Fish Restoration Act administered through the Delaware Department of Natural Resources and Environmental Control.

\section{LITERATURE CITED}

Boisclair, D., Leggett, W. C. (1989). Among-population variability in fish growth: influence of prey type. Can. J. Fish. Aquat. Sci. 46: 468-482

Brett, J. R., Groves, T. D. D. (1979). Physiological energetics. In: Hoar, W. S., Randall, D. J. (eds.) Fish physiology, Vol. 8. Academic Press, Inc, Orlando, p. 279-352

Checkley, D. M. (1982). Selective feeding by Atlantic herring (Clupea harengus) larvae on zooplankton in natural assemblages. Mar. Ecol. Prog. Ser. 9: 245-253

Cope, J. S. (1991). Effects of prey density on growth and survival of larval weakfish (Cynoscion regalis) in fielddeployed enclosures and in laboratory aquaria. M.Sc. thesis, College of Marine Studies, Univ. of Delaware, Lewes

Dill, L. M. (1983). Adaptive flexibility in the foraging behavior of fishes. Can. J. Fish. Aquat. Sci. 40: 398-408

Dutton. P. (1992). Effects on experience on feeding success by larval white seabass, Atractoscion nobilis. J. Fish. Biol. 41 $765-773$

Epifanio, C. E. (1987). The role of tidal fronts in maintaining patches of brachyuran zoeae in estuarine waters. J. Crust. Biol. 7: 513-517 
Goshorn, D. M. (1990). Distribution of larval weakfish (Cynoscion regalis) in Delaware Bay and the relationship of field prey concentration to laboratory determined growth and mortality rates. Ph.D. dissertation, College of Marine Studies, Univ. of Delaware, Lewes

Goshorn, D. M., Epifanio, C. E. (1991). Diet of larval weakfish and prey abundance in Delaware Bay. Trans. Am. Fish. Soc. 120: $684-694$

Govoni, J. J., Hoss, D. E., Chester, A. J. (1983). Comparative feeding of three species of larval fishes in the northern Gulf of Mexico: Brevoortia patronus, Leiostomus xanthurus, and Micropogonias undulatus. Mar. Ecol. Prog. Ser. 13: $189-199$

Govoni, J. J., Ortner, P. B., Al-Yamani, F., Hill, L. C. (1986). Selective feeding of spot, Leiostomus xanthurus, and Atlantic croaker, Micropogonias undulatus, larvae of the northern Gulf of Mexico. Mar. Ecol. Prog. Ser. 28: 175-183

Hansen, M. J., Wahl, D. H. (1981). Selection of small Daphnia pulex by yellow perch fry in Oneida Lake, New York. Trans. Am. Fish. Soc. 110: 64-71

Houde, E. D. (1987). Fish early life dynamics and recruitment variability. Am. Fish. Soc. Symp. 2: 17-29

Hunter, J. R. (1980). The feeding behavior and ecology of marine fish larvae. In: Bardach, J. E., Magnuson, J. J., May, R. C., Reinhart, J. M. (eds.) Fish behavior and its use in the capture and culture of fishes. ICLARM Conf. Proc. 5, International Center for Living Aquatic Resources Management, Manila, p. 287-330

Lindberg, J. C., Doroshov, S. I. (1986). Effect of diet switch between natural and prepared foods on growth and survival of white sturgeon juveniles. Trans. Am. Fish. Soc 115: $166-171$

This article was presented by R. B. Forward $J_{T}$, Beaufort, N. Carolina, USA
Mathias, J. A., Li, S. (1982). Feeding habits of walleye larvae and juveniles: comparative laboratory and field studies. Trans. Am. Fish. Soc. 111: 722-735

Mercer, L. P. (1983). A biological and fisheries profile of weakfish, Cynoscion regalis. Spec. Scientific Rep. No. 39 North Carolina Dept Natural Resources and Community Development, Division of Marine Fisheries, Morehead City, NC

Mills, E. L., Widzowski, D. V., Jones, S. R. (1987). Food conditioning and prey selection by young yellow perch (Perca flavescens). Can. J. Fish. Aquat. Sci. 44: 549-555

O'Brien, W. J., Browman, H. I., Evans, B. I. (1990). Search strategies of foraging animals. Am. Scient. 78: 152-160

Pryor, V. K., Epifanio, C. E. (1993). Prey selection by larval weakfish (Cynoscion regalis): the effects of prey size, speed, and abundance. Mar. Biol. 116:31-37

Pyke, G. H., Pulliam, H. R., Charnov, E. L. (1977). Optimal foraging: a selective review of theory and tests. Q. Rev. Biol. 52: $137-154$

Rice, W. R. (1990). A consensus combined p-value test and the family-wide significance of component tests. Biometrics 46: $303-308$

Stephens, D. W., Krebs, J. R. (1986). Foraging theory. Princeton University Press, Princeton

Stoecker, D. K., Govoni, J. J. (1984). Food selection by young larval gulf menhaden (Brevoortia patronus). Mar. Biol. 80: 299-306

Ware, D. M. (1971). Predation by rainbow trout (Salmo gairdneri): the effect of experience. J. Fish. Res. Bd Can. 28: $1847-1852$

Zai, J. H. (1984). Biostatistical analysis, 2nd edn. PrenticeHall, Inc., Englewood Cliffs

Manuscript first received: March 16, 1993

Revised version accepted: August 17, 1993 